\title{
Qualitative Research Methods in
}

\section{Drug Abuse and AIDS}

\section{Prevention Research: An}

\section{Overview}

\section{Robert G. Carlson, Harvey A. Siegal, and Russel S. Falck INTRODUCTION}

Almost two decades ago, at the first workshop/technical review on qualitative research methods and ethnography sponsored by the National Institute on Drug Abuse (NIDA), Siegal (1977, p. 79) remarked that despite the existence of numerous excellent qualitative studies on drug abuse, “Ethnographers have had difficulty explaining precisely what they do.” In the intervening years, qualitative research methods have gained increasing importance as a systematic means of data collection and analysis that have become critical dimensions in drug abuse and AIDS research (Lambert 1990). For example, qualitative and ethnographic research are key components in NIDA's recent program announcement, "Strategies to Reduce HIV Sexual Risk Practices in Drug Users.”

Moreover, through the National AIDS Demonstration Research Program (Brown and Beschner 1993) and the Cooperative Agreement for AIDS Community-Based Outreach/Intervention research initiative, qualitative methodologists, or ethnographers. have worked increasingly on research teams composed of epidemiologists, statisticians, health educators, and psychologists, thereby promoting interdisciplinary cooperation. The recent publication of Denzin and Lincoln’s (1994a) compendium, "Handbook of Qualitative Research,” emphasizes this momentum toward interdisciplinary understanding.

Despite the increased receptivity toward qualitative research methods, however, there is still some lack of clarity in what qualitative methodologists do. This chapter presents an overview of what qualitative research methods are, how they are used, and the key features required for their successful application. The ways in which qualitative methods contribute to the goal of preventing and treating drug abuse as well as associated problems, such as HIV infection, are emphasized. 


\section{DEFINING QUALITATIVE RESEARCH METHODS}

Feldman and Aldrich (1990) date the beginnings of modem qualitative research on drugs to De Quincey’s “Confessions of an English Opium Eater,” published in 1822, in which the author took on the role of participant observer among eminent addicts and recorded his observations.

Since that time, qualitative research methods have become more systematically defined in the fields of anthropology and sociology (Agar 1980, 1986; Bernard 1988; Denzin 1970, 1989; Glaser and Strauss 1967; Naroll and Cohen 1973; Pelto and Pelto 1973, 1978; Strauss and Corbin 1990; Vidich and Stanford 1994; Werner and Schoepfle 1987a, 1987b).Appropriately applied, qualitative research methods are neither soft science nor the mere journalistic reporting of values, beliefs, and behaviors. Moreover, through their capacity to expose the hidden worlds of drug users and those close to them in their holistic contexts, qualitative and quantitative methods can complement one another.

As Denzin and Lincoln (1994b) note, the word “qualitative” implies an emphasis on process and an indepth understanding of perceived meanings, interpretations, and behaviors, in contrast with the measurement of the quantity, frequency, or even intensity of some externally defined variables. Since qualitative methods have different meaning for different people-depending on a person's intellectual background, research problem, and theoretical interests-it is worthwhile to examine several definitions.

According to Denzin and Lincoln (1994b, p. 2): Qualitative researchers study things in their natural settings, attempting to make sense of, or interpret, phenomena in terms of the meanings people bring to them. Qualitative research involves the studied use of a variety of empirical materials-case study, personal experience, introspective, life story, interview, observational, historical, interactional, and visual texts-that describe routine and problematic moments and meanings in individuals' lives.

The keys here are emphasis on deriving an understanding of how people perceive and construct their lives as meaningful processes, how people interact with one another and interpret those interactions in the context of the social and natural worlds, and the importance of observation in natural settings. As such, the central methods of qualitative research include interviewing people through various techniques and recording what they say, observing people in the course of their daily routines, and recording their behaviors.

Strauss and Corbin (1990, pp. 17-18) offer an even broader definition of qualitative methods in the course of developing the methodology of grounded theory: "By qualitative research we mean any kind of research that produces findings not arrived at by means of statistical procedures or 
other means of quantification.” Strauss and Corbin (1990) note, however, that some researchers employ qualitative interviewing techniques to gather textual data that are subsequently coded and analyzed statistically; in effect, they quantify qualitative data. Other qualitative metbodologists (Bernard 1988; Trotter and Potter 1993; Weller and Romney 1988) employ systematic interviewing techniques, such as triad sorting, to produce data that are analyzed quantitatively. The results of such analyses generate an understanding of cognitive categories, or how people perceive the relationship among categories in some domain, such as HIV risk behaviors. Traditionally, the process of describing and analyzing how people perceive the world and their behaviors has been the goal of professional ethnographers trained in anthropology and sociology. While ethnography is often equated with the practice of qualitative methodologies (Brooks 1994; Werner and Schoepfle 1987a), this chapter returns to the distinction between the two (below).

Wiebel (1990) identifies two reasons why qualitative methods are significant for drug abuse research. First, the construction of meaningful, structured questionnaires amenable to statistical analysis requires that a researcher possess significant familiarity with the way targeted $r$ espondents perceive their world. Implicit, then, is the importance of conducting qualitative research in the early phases of a research project.

Second, Wiebel (1990, p. 5) suggests that "Qualitative research is often the only means available for gathering sensitive and valid data from otherwise elusive populations of substance abusers.” By contrast, Werner and Schoepfle (1987a) emphasize that qualitative research is necessary not only to design questionnaires but also to formulate meaningful research questions, conduct appropriate statistical analyses, and interpret the results. By way of analogy, a biologist would not design an experiment without first having an extensive knowledge of the physiology, life cycle, and ecology of some species he or she was interested in learning something more about. This background knowledge, as well as more specific knowledge at different levels (e.g., biochemical processes), is often available to a scientist in previously published research. The crucial problem in drug abuse and AIDS prevention research is that such background knowledge is often not sufficiently available to conduct meaningful research, especially given the ever-changing drug scene, as recently manifested in the rapid uptake in crack cocaine use among injection drug users (IDUs) and the significance of contextual or geographic variability (e.g., Siegal et al. 1994; Singer et al. 1992).

Few people would argue with the assertion that drug abuse, and the increased frequency of HIV risk behaviors sometimes associated with it, are deeply enmeshed in peoples' daily routines. Qualitative methodologists assume that there are systematic patterns to the way drug abusers 
create meaning in their lives, perceive their place within society, and behave. They also assume that such knowledge may be patterned by gender, ethnicity, class, geographic context, and so on. Through qualitative methods, it is possible to gain an understanding of the meanings people attribute to their actions as well as delineate the wider sociopolitical and ecological context in which drug use and HIV risk behaviors take place. Such an understanding is crucial not only for designing and evaluating questionnaires but also for designing locally and culturally sensitive intervention and prevention programs as well as for formulating meaningful research questions (Carlson et al. 1994a) Critical to qualitative methods, then, is actively listening to people and recording what they say about their lives as well as observing and recording what they actually do. Of course, what people say they do and their actual behaviors may not always be consistent. Qualitative methods may reveal these inconsistencies through the combination of participant observation research and interviewing (Page 1990). At least in the initial phases of most qualitatively oriented research, description and interpretation take precedence over measurement and prediction (Agar 1980; Brooks 1994). For some research problems qualitative methods and analyses can be ends in themselves; for others, qualitative research is a necessary precursor to the construction of alternative systematic means of testing hypothesized patterned relationships among concepts that emerge during the course of data analysis (Agar 1980). Whatever the case, there are several requirements to be met if qualitative methods are to be appropriately applied.

\section{REQUIREMENTS FOR A QUALITATIVE RESEARCH PERSPECTIVE}

Qualitative research methods are not techniques that can be deployed haphazardly, nor are they techniques to be assigned secondary significance compared to alternative methodological approaches. A total commitment of time and energy is required of the qualitative researcher, at least initially, to develop and maintain relationships with as large and diverse a number of people as possible. In the words of Sterk-Elifson (1993, p. 163), “Qualitative research requires the investigator to spend considerable time with the group under study, to develop contacts with key respondents, to learn the language, norms, values, and attitudes of this group, and to build trust relationships.” The authors would add that an amount of time equal to that devoted to data collection must be devoted to data processing and analysis. Beyond the requirements of time, Ruckdeschel (1985) identifies several assumptions that underlie the "qualitative research perspective.” First, it is assumed that people are symbol constructing and spend a great deal of time consciously and unconsciously interpreting what the symbols and behaviors created by themselves and others mean. Second, qualitative methodologists gain knowledge of how people think and behave through involvement in their daily social milieus. Finally, it is assumed that 
people's perceptions and behaviors are related in some way to context at varying levels of specificity (e.g., the family, the community, cultural or ethnic tradition, history, political economy).

Agar (1977) adds further specificity to a qualitative research perspective through a closer examination of the kind of relationships that qualitative researchers need to create with the people under study. Referring to Bateson's (1972a) distinction between symmetrical and complementary relationships, Agar (1977) argues that qualitative research must be based on creating complementary relationships with informants.' In Agar's (1977, p. 147) words: Rather than beginning with a systematic deductive framework, the researcher sets out to learn the framework of a group. Rather than entering into communication with group members with a list of variables and hypothetical relationships, he enters to learn what the group members themselves define as significant "variables” and "relationships” among the variables.

As such, the researcher surrenders control of the relationship to a degree; in order to learn, he or she must assume a position of subordination or complementarity (Agar 1977, 1980). A complementary relationship contrasts with a symmetrical relationship in several ways. In a symmetrical relationship, often associated with deductive logic and received science (Agar 1986), the conditions of the interaction between the researcher and participant, as well as the response categories of the questionnaire, are controlled by the researcher. As Agar $(1977,1980)$ clarifies, a qualitative researcher may take on symmetric relations with respondents in the later phases of a research project through conducting systematic tests of hypotheses, after an initial period of learning what makes sense to people from their perspectives.

The application of qualitative methods signifies the attribution of value to the meaningful, patterned ways in which other people behave and interpret their lives. Qualitative methods can, therefore, appear disorienting to those who are unfamiliar with their use, because they require stepping out of one's usual framework for making sense of daily life and stepping into the unfamiliar world of others. In some cases, peoples' behaviors and interpretations about why they do or do not do certain things may be inconsistent with what might be called mainstream norms and values or even the scientific perspective about another group's culture or worldview. Consequently, the results of qualitative research may require reconceptualization of mainstream values and perspectives or the examination of the underlying reasons for those perspectives. Qualitative methodologists are mediators who attempt to demonstrate how a particular way of life makes sense in reference to another way of understanding and creating social reality (Agar 1986). Newman and colleagues (1991), for example, discuss the ways in which the qualitative understanding of the meaning of HIV risk behaviors from various people's own perspectives may 
be integrated with the epidemiologic assessment of the transmission patterns of sexually transmitted diseases.

Alperin and Needle (1991) and Williams and Johnson (1993) focus on the value of obtaining a qualitative understanding of social networks both for designing interventions and for epidemiologic understanding of the natural history of HIV seroprevalence rates in various locales (Carlson et al. 1994a; Siegal 1990). As Clatts observed (1991, p. 232, note 6), "It is precisely the process of traversing socially derived boundaries that becomes the primary task of the ethnographer" or qualitative methodologist. Preconceived notions of the worldview of drug users must be cast aside when conducting qualitative research, or at least the ways that these may bias the elicitation of data must be acknowledged. In other words, qualitative methodologists must take care to let people speak for themselves and not impose their beliefs or values on the data.

In summary, the formal application of qualitative methods implies a set of assumptions about the nature of human behavior, the meanings created through it, and how to learn more about such phenomena. The design of structured questionnaires, interventions, and prevention initiatives can be improved and made locally effective through such detailed, descriptive, contextual, and relational knowledge about peoples' daily lives. Several key components of qualitative research are reviewed below.

\section{ETHICS AND INFORMED CONSENT}

Because appropriately conducted qualitative methods are highly invasive of intimate aspects of peoples' lives, great care must be taken in the protection of research participants. Most qualitative researchers are committed to abide by a set of guidelines of professional ethics (Agar 1980; American Anthropological Association 1990; Bernard 1988; Punch 1994; Society for Applied Anthropology 1991; Soloway and Walters 1977; Weppner 1977a). Three points are basic to these guidelines. First, the purposes of the research and potential risks to the subjects must be made explicit to them; in addition, people must have the right to choose whether or not to participate. Second, the researcher must determine that no harm can come to the individual study subjects as a result of their participation in the research. Third, the researcher must ensure that the resulting research and publications cannot be used in such a way that they may bring harm to the participants as a group.

Central to achieving these goals is the use of an informed consent form in which the guidelines of the research and the person's role in it are described. Particularly in cases where illegal and ighly personal behaviors are the subject of research, a Federal grant of confidentiality is of crucial value for protecting highly sensitive data. In the case of fairly controlled interview situations, the use of a signed informed consent form is recommended. In the case of participant observation situations 
in which the qualitative methodologist is interacting with people in more public settings, it is incumbent upon the researcher to make the objectives clear, to respect an individual's wish not to participate, and to leave the scene if necessary. Compensating participants for the time devoted to answering research questions is an important consideration (Weppner 1977a; Wiebel 1990). Once ethical issues are considered and a guideline for informed consent decided upon, data collection may begin in one of two general forms, either separately or in combination: participant observation and interviewing.

\section{PARTICIPANT OBSERVATION AND FIELDWORK}

Participant observation is a qualitative research technique that usually guides ethnographic fieldwork (Adler and Adler 1994; Agar 1980; Bernard 1988; Pelto and Pelto 1973, 1978). It means becoming a part of peoples' lives to the extent that it is practically, legally, and ethically possible and, while interacting with them, observing their behaviors and conversations.

Participant observation, then, is a dialectic process that cycles back and forth between assuming the role of a participant and the role of an observer. Data from observations and conversations are usually recorded in fieldnotes from recall after the researcher has left the social situation. These may include sketches or maps of activity areas.Although participant observation is generally considered a qualitative research method, observations of IDUs frequenting a shooting gallery, for example, can be quite systematic by randomizing time of day and day of the week when observations are made (Carlson et al. 1994a). The significance of participant observation for revealing unrecognized pathways for HIV transmission among IDUs and documenting needle circulation and bleach-cleaning patterns stands as a recent example of the value of this method (Jose et al. 1993; Koester and Hoffer 1994; Price 1993).

It is important to emphasize that appropriately conducted participant observation techniques require professional training and the allocation of the lead time necessary to develop rapport with the people being studied. Developing rapport means creating and maintaining complementary relationships with people. Building relationships can contribute to the execution of qualitative interviews in more controlled settings.

\section{QUALITATIVE INTERVIEWS}

A number of qualitative interviewing techniques exist, ranging from informal interviews to semistructured interviews and life histories (Agar 1980; Bernard 1988; Clatts 1991; Denzin 1970, 1989; Fontana and Frey 1994; Glaser and Strauss 1967; Pelto and Pelto 1978). With the possible exception of various systematic, cognitive elicitation techniques mentioned above (Weller and Romney 1988), their unifying feature is the collection of textual data through audiotape recording or note taking (Ives 1980). In the open-ended interview format, conversation is allowed to 
flow freely in reference to a particular topic. By contrast, in a more structured interview, a set of predesigned discussion topics are offered for a person’s response. In general, open-ended interviewing serves as a means of determining how people talk about or perceive various aspects of their lives and how they categorize things. After preliminary analysis, these data may be employed to create a more focused set of questions that pertain to a particular research problem or topic (Agar 1980).

For those unfamiliar with qualitative research methods, interviewing may suggest something less than science, such as mere conversation or even journalistic reporting. But free-flowing conversation, or informal interviewing, plays an important role in gaining familiarity with the way people perceive and express various dimensions of their lives. They must be listened to carefully and assimilated, either in the context of participant observation or individual interview sessions. At the same time, more formal interviewing techniques require substantial preparation on the part of the qualitative methodologist. As Agar $(1977,1980)$ emphasizes repeatedly, the researcher must carefully encourage individuals to talk about themselves; to do so. respondents must believe in the sincerity of the interviewer's learning role and that the interviewer attributes significance to their beliefs, behaviors, and patterns of perception. The skills required to draw an individual's interpretations, values, and beliefs out into the open require professional training and practice (Sitton et al. 1983; Survey Research Center 1966).

In some cases, focus groups, or group discussions of three to six or more respondents, can take the place of individual open-ended interviews. Both interviewing techniques allow for the general discussion of research questions. Focus groups can be used to refine interventions, to explore research topics, to guide the refinement of more structured interviews, to obtain feedback on the design and evaluation of quantitative survey instruments, and even to obtain feedback on preliminary analyses (Ashery et al. 1995; Kruger 1988; Merton 1946; Morgan 1988; O’Brien 1993; Stewart and Shamdasani 1988).

\section{ANALYZING TEXTUAL DATA}

Although the conduct of qualitative interviews may appear scattered, unsystematic, or even daunting to professionals unfamiliar with the techniques, what the researcher does with the textual data once they are collected may appear even more so. It was mentioned above that textual data are sometimes quantified,' but the analysis of texts usually differs significantly from quantitative or statistical analyses. In general, what is required for the analysis of texts and observational data is some means of discovering systematic patterns or relationships among categories (Agar 1980). 
The most important initial means of discovering patterns is to gain familiarity with the texts by reading and re-reading the documents. There is no substitute for this time-consuming, intensive dimension of data analysis. It is often facilitated in part by the laborious task of transcribing audiotapes or verifyying initial transcriptions. Further examination of patterns is usually performed by some method of indexing or coding of categories. In most instances, the categories emerge from the data in the form of patterns or relationships that are repeated across a range of respondents. In other instances, categories may be employed because they are relevant to a particular research problem or theoretical interest. Indexing and coding may include taking notes on a specific topic from the texts, actually cutting out sequences of text and then filing them by category (Agar 1980), and using computer software specifically designed for indexing and text retrieval (Boone and Wood 1992; Fielding and Lee 1991; Fritz 1990; Pfaffenberger 1988; Richards and Richards 1994).

The next problem to resolve is what to do with the patterns and relationships once they are recognized. In the case of the methodology of grounded theory, for example, the patterned relationships among conceptual categories assigned to the data by the analyst are articulated in a more formal statement or theory (Glaser and Strauss 1967; Strauss and Corbin 1990, 1994). In other cases, patterns and relationships may be analyzed with respect to a specific theoretical perspective. Several additional strategies raise the issues of validity, sampling, and the complementary relationship between qualitative and quantitative methodologies. The criteria for evaluating the results of qualitative research are quite different from, but no less systematic or scientific than, statistical hypothesis testing. To begin, a hunch that a meaningful pattern has been discovered is just an initial step in the qualitative research process. Systematic patterns and relationships are continuously formulated, tested, and modified as qualitative data are collected (Agar 1980; Glaser and Strauss 1967).

Moreover, the researcher must always be conscious of the nature of the developing sample in relation to the known and emerging conceptions of the characteristics of the general population (Biemacki and Waldorf 1981). For example, a researcher is interested in needle transfer patterns among IDUs. After conducting semistructured interviews with 10 African- American women and 10 African-American men who inject heroin, the researcher repeatedly hears similar explanations regarding why the respondents generally do not value using needles that have been used repeatedly by others. To further test and perhaps generalize this emergent pattern, the researcher seeks out 10 African-American men and 10 African-American women who inject cocaine to interview using the same interview guidelines. Later, the researcher might shift attention to other ethnic groups in the research location to further explore and modify the initial findings. 
Glaser and Strauss (1967) refer to the process of moving among groups as "theoretical sampling," or, using Denzin’s (1970) term, “data triangulation.” When a qualitative researcher has worked among a sufficient number of individuals generally thought to reflect the known diversity of the population and similar instances of a pattern are found repeatedly, Glaser and Strauss (1967) refer to this as "theoretical saturation.” Both procedures complement one another. At some point in the research process, perhaps at the point of the theoretical saturation of some category or topic, a qualitative methodologist may attempt to increase confidence in the validity and generalizability of the findings by employing different methodological techniques. Denzin (1970) describes this procedure as methodological triangulation.3 In the case mentioned above, the researcher might formulate questions about why IDUs transfer used needles and about their attitudes toward this behavior as a set of structured questions for administration to a larger sample (Carlson et al., under review). The results, of course, would suggest whether there is increased support for a hypothesized pattern to the values IDUs attribute to needle sharing or whether it should be modified or rejected. The experienced qualitative researcher is continuously seeking data from different sources to support, modify, or reject emergent patterns and relationships. This leads the discussion to the relationship between qualitative methods and ethnography.

\section{QUALITATIVE RESEARCH METHODS AND ETHNOGRAPHY}

As mentioned in the introduction, qualitative methods are often equated with ethnographic research. This is not surprising, since the people having the necessary professional training to adequately conduct qualitative research are most often ethnographers having a background in anthropology or sociology.4 Ethnographers are trained to conduct participant observation fieldwork, to conduct qualitative interviews, and to analyze their data to produce systematic descriptions of a people's lifeway or culture. According to James (1977, p. 180), “Ethnography is the study of culture from within, the attempt through field observation to record how individuals perceive, construct, and interact within their social and economic environment.” Conducting ethnographic research may be characterized as a life journey writ small-an intense, yet extended, immersion in the collection of texts and the recording of observations and experiences in fieldnotes. According to Agar (1986, p. 12), "Such work requires an intensive personal involvement, an abandonment of traditional scientific control, an improvisational style to meet situations not of the researcher's making, and an ability to learn from a long series of mistakes.” This process is interactively influenced by the ethnographer's constant thinking and rethinking of incoming data and a deepening familiarity with previously published research, secondary data sources, research problems, and theory. As Fritz (1990, p, 61) phrased this process: The ethnographer is always "working with the data;" that is, thinking and wondering 
about meanings, relationships, and explanations. By continually constructing and testing working hypotheses, the ethnographic analyst maintains an intimate familiarity with the data, generates new interpretations of field evidence, and plots new directions for further field exploration. The process of conducting ethnographic research involves all of this.

Ideally, its end result is the production of an ethnography, a monograph length systematic description and analysis of a people's culture (symbolic meanings, beliefs, attitudes, and behaviors) that is oriented by a particular research problem and theory. It was also mentioned in the introduction that the conduct of qualitative research requires a significant investment of time that is essential for developing the kinds of relationships with participants that are needed.

As such, with the possible exception of focus groups in certain situations, the conduct of qualitative methods in the absence of an extended background period of ethnographic research would contradict the essence of the qualitative research perspective as formulated here.

\section{CONCLUSION}

To conclude, the key features of qualitative methods as outlined above are summarized. First, qualitative research is largely an inductive process by which a scientist attempts to gain an understanding of the patterned meanings, perceptions, beliefs, values, and behaviors of a particular group of human beings in relation to a research problem. Although not always the case, a qualitative methodologist is unlikely to begin and end a research effort with a deductive theory, construct a questionnaire, and test hypotheses (Agar 1980). Because qualitative methods are designed to capture a people's way of conceptualizing their lives, strategies for living, and argot in relationship to contexts at varying levels of specificity, these data are crucial for the design and evaluation of meaningful (both to the respondents and the scientist) questionnaires, drug abuse and HIV risk reduction interventions, and prevention initiatives (Brooks 1994). In short, qualitative research is necessary to make public health goals culturally meaningful and effective at the local level (Singer 1991).

Second, in their most generic form, qualitative methods include participant observation and the collection of texts through interviews.

Both of these methods require that the ethnographer adopt the role of one who has something to learn from the way other people perceive the world and behave-that is, the role of one who attempts to create complementary rather than strictly symmetric relations with the people whom one is interested in knowing more about. In addition, the analysis of qualitative data is systematic and rigorous when conducted appropriately. 
Third, in relation to drug use and HIV risk behaviors in particular, qualitative research implies a progressive, phased research design (Agar 1980) in which a research team ideally moves from gaining indepth knowledge of a particular phenomenon or target group to the construction of meaningful, culturally sensitive, quantitative questionnaires (Serrano et al. 1993). Given the adequate lead time required, hypothesized patterns or relationships discovered through the analysis of textual and observational data may be further evaluated through quantitative methods as well (Booth et al. 1993). On the other hand, the process of formulating questions related to broader theories of human behavior, such as addiction, also can be enhanced by qualitative or ethnographic background knowledge.

Fourth, ethnographic research is necessary to monitor rapidly changing drug-use patterns and HIV risk behaviors (Carlson and Siegal 1991). Such data are crucial for providing a rapid response to changing interactions among different people at risk. Finally, it was mentioned that the inductive nature of qualitative research means that some of the specifics of the research process cannot be formulated in advance. It is precisely the creative discovery process inherent in qualitative research that makes it both exciting and of tremendous scientific value. Ideally, qualitative researchers, or ethnographers, are skilled in discovering connections or relationships within and among different domains. Through gaining holistic knowledge in different domains, they are able to specify what contextual features are relevant to understanding a particular research problem. This requires them to mediate not only social and cultural boundaries in the field but also disciplinary boundaries in the course of their work (Agar 1986; Clatts 1991; Carlson et al. 1992; Carlson et al. 1994b). To the extent that one can gain knowledge of drug use in the field, the basic principles of statistics, a working knowledge of theories of addiction, drug treatment, and the epidemiology of the HIV disease, the ethnographer will be highly capable of designing and conducting meaningful and practical research.

\section{NOTES}

1. Agar (1977) refers to a contrast between symmetrical and asymmetrical relations in referring to Bateson's (1972b) more general work. This chapter refers to the contrast Bateson (1972a) made between complementary and symmetrical relations. Consequently, complementary relations refer to Agar's (1977) symmetrical relations, and the use of the term symmetrical relations in this chapter refers to Agar's (1977) conception of asymmetrical relations. Interested readers should consult Bateson (1972a, 1972b).

2. The authors are not familiar with any published research in the field of drug abuse or AIDS that employs statistics to manipulate textual 
data.

3. See Denzin (1989) for a detailed, updated discussion of methodological triangulation and the issue of validity.

4. See Akins and Beschner (1980); Feldman and Aldrich (1990);

Hughes (1977); and Weppner (19776) for discussions of ethnography and drug abuse research. REFERENCES

Adler, P.A.. and Adler, P. Observational techniques. In: Denzin, N., and Lincoln, Y., eds.

Handbook of Qualitative Research. Thousand Oaks,CA: Sage Publications, 1994. pp. 377-392.

Agar, M. Ethnography in the streets and in the joint. In: Weppner, R., ed.Street Ethnography:

Selected Studies of Crime and Drug Use in Natural Settings. Beverly Hills, CA: Sage

Publications, 1977.pp. 143-156.

Agar, M. The Professional Stranger: An Informal Introduction to

Ethnography. New York: Academic Press, 1980.

Agar, M. Speaking of Ethnography. Sage University Paper Series on

Qualitative Research Methods. Vol. 2. Beverly Hills, CA: Sage

Publications, 1986.

Akins, C., and Beschner, G., eds. Ethnography: A Research Tool for

Policymakers in the Drug and Alcohol Fields. DHHS Pub. No (ADM)80-946. Washington, DC:

Supt. of Docs., U.S. Govt. Print.Off., 1980.

Alperin, S., and Needle, R. Social network analysis: An approach for understanding IV drug users. In: National Institute on Drug Abuse.

Community-Based AIDS prevention: Studies of Intravenous Drug

Users and Their Sexual Partners. DHHS Pub. No. (ADM)91-1752.

Washington, DC: Supt. of Docs., U.S. Govt. Print. Off., 1991.

pp. 217-224.

American Anthropological Association. Professional Ethics: Statements

and Procedures of the American Anthropological Association.Washington, DC: American

Anthropological Association, 1990.

Ashery, R.; Carlson, R.; Falck, R.; and Siegal, H. Injection drug users, crack-cocaine users, and human service utilization: An exploratory study. Soc Work 40:75-82, 1995.

Bateson, G. The cybernetics of "self': A theory of alcoholism. In: Bateson, G. Steps to an Ecology of Mind. New York: Ballantine Books, 1972a. pp. 309-337.

Bateson, G. Steps to an Ecology of Mind. New York: Ballantine Books, 1972b.

Bernard, H. Research Methods in Cultural Anthropology. Newbury Park, CA: Sage Publications, 1988. 
Biemacki, P., and Waldorf, D. Snowball sampling: Problems and techniques of chain referral sampling. Social Methods Res10:141-163, 1981.

Boone, M., and Wood, J. Computer Applications for Anthropologists.

Belmont, CA: Wadsworth Publishing Company, 1992.

Booth, R.; Koester, S.; Reichardt, C.; and Brewster, T. Qualitative and quantitative methods to assess behavioral change among injection

drug users. In: Fisher, D., and Needle, R., eds. AIDS and Community- Based Drug Intervention

Programs: Evaluation and Outreach. New York: The Haworth Press, 1993. pp. 161-183.

Brooks, C. Using ethnography in the evaluation of drug prevention and intervention programs. Int J Addict 29(6):791-801, 1994.

Brown, B., and Beschner G., eds. Handbook on Risk of AIDS: Injection Drug Users and Sexual Partners. Westport, CT: Greenwood Press, 1993.

Carlson, R., and Siegal, H. The crack life: An ethnographic overview of crack use and sexual behavior among African Amercians in a Midwest metropolitan city. J Psychoactive Drugs 23:1120, 1991.

Carlson, R.; Siegal, H.; and Falck, R. Ethnography, epidemiology, and public policy: Needle use practices and HIV risk reduction among injecting drug users in the Midwest. In: Feldman, D., ed. Global AIDS Policy. Westport, CT: Bergin and Garvey, 1994a. pp. 185-214.

Carlson, R.; Seigal, H.; Wang, J.; and Falck, R. Attitudes toward needle “sharing” among injection drug users: Combining qualitative and quantitative research methods. Hum Organ, under review.

Carlson, R.; Siegal, H.; Baumgartner, K.; Falck, R.; and Rapp, R. Taking the pulse of the project: The multifaceted role of ethnography in the Dayton/Columbus NADR project. In: National Institute on Drug Abuse. Community-Based AIDS Prevention Among Intravenous Drug Users and Their Sexual Partners: The Many Faces of the HIV Disease. Proceedings of the First Annual National AIDS . Demonstration Research National Meeting. Bethesda, MD: NOVA Research Company, 1992. pp. 145-152.

Carlson, R.; Wang, J.; Siegal, H.; Falck, R.; and Guo, J. An ethnographic approach to targeted sampling: Problems and solutions in AIDS prevention research among injection drug and crackcocaine users.Hum Organ 53:279-286, 1994b.

Clatts, M. Ethnography and AIDS intervention in New York City: The use of life history as a research strategy. In: National Institute on Drug Abuse. Community-Based AIDS Prevention: Studies of Intravenous Drug Users and Their Sexual Partners. DHHS Pub. No. (ADM) 91-1752. Washington, DC: Supt. of Docs.. US. Govt. Print. Off., 1991. pp. 225-233. 
Denzin, N. The Research Act. Chicago: Aldine, 1970.

Denzin, N. The Research Act. 3d ed. Englewood Cliffs, NJ: Prentice Hall, 1989.

Denzin, N., and Lincoln, Y., eds. Handbook of Qualitative Research.Thousand Oaks, CA: Sage Publications, 1994a.

Denzin, N., and Lincoln, Y. Introduction: Entering the field of qualitative research. In: Denzin, N., and Lincoln, Y., eds. Handbook of Qualitative Research. Thousand Oaks, CA: Sage publications, 1994b. pp. 1-17.

Feldman, H., and Aldrich, M. The role of ethnography in substance abuse research and public policy: Historical precedent and future prospects. In: Lambert, E., ed. The Collection and interpretation of Data from Hidden Populations. National Institute on Drug Abuse Research Monograph 98. DHHS Pub. No. (ADM)90-1678. Washington, DC: Supt. of Docs., U.S. Govt. Print. Off., 1990. pp. 12-30.

Fielding, N., and Lee, R., eds. Using Computers in Qualitative Research. Newbury Park, CA: Sage Publications, 1991.

Fontana, A., and Frey, J. Interviewing: The art of science. In: Denzin, N.,and Lincoln, Y., eds. Handbook of Qualitative Research. Thousand Oaks, CA: Sage Publications, 1994. pp. 361-376.

Fritz, R. Computer analysis of qualitative data. In: Lambert, E., ed. The Collection and Interpretation of Data from Hidden Populations National Institute on Drug Abuse Research Monograph 98. DHHS Pub. No. (ADM)90-1678. Washington, DC: Supt. of Docs., U.S.

Govt. Print. Off., 1990. pp. 59-79.

Glaser, B., and Strauss, A. The Discovery of Grounded Theory: Strategies for Qualitative Research. Chicago: Aldine, 1967.

Hughes, P. Behind the Wall of Respect: Community Experiments in Heroin Addiction Control. Chicago: University of Chicago Press, 1977.

Ives, E. The Tape-Recorded Interview. Knoxville, TN: The University of Tennessee Press, 1980. James, J. Ethnography and social problems. In: Weppner, R., ed. Street Ethnography: Selected Studies of Crime and Drug Use in Natural Settings. Beverly Hills, CA: Sage Publications, 1977. pp. 179-200.

Jose, B.; Friedman, S.; Neaigus, A.; Curtis, R.; Grund, J-P.;Goldstein, M.; Ward, T.; and Des Jarlais, D. Syringe-mediated drug sharing (backloading): A new risk factor for HIV among injecting drug users. AIDS 7:1653-1660, 1993.

Koester, S., and Hoffer, L. The mechanics of drug injection: Additional HIV risks. AIDS Public Policy 9:100-105, 1994.

Kruger, R. Focus Groups: A Practical Guide for Applied Research. Newbury Park, CA: Sage Publications, 1988. 
Lambert, E., ed. The Collection and Interpretation of Data from Hidden Populations. National Institute on Drug Abuse Research Monograph 98. DHHS Pub. No. (ADM)90-1678. Washington, DC: Supt. Of Docs., U.S. Govt. Print. Off., 1990.

Met-ton, R. The focused interview. Am J Social 51:541-557, 1946.

Morgan, D. Focus Groups as Qualitative Research. Sage University

Paper Series on Qualitative Research Methods. Vol. 16. Newbury Park, CA: Sage Publications, 1988.

Naroll, R., and Cohen, R., eds. Handbook of Methods in CulturalAnthropology. New York: Columbia University Press, 1973.

Newman, L.; Zierler, S.; and Cheung, D. Epidemiological and ethnographic methods for research in high-risk behavior: Integrated approaches to acceptability and intervention. In: Wasserheit, J.; Aral, S.; Holmes, K.; and Hitchcock, P., eds. Research Issues in Human Behavior and Sexually Transmitted Diseases in the AIDS Era.

Washington, DC: American Society for Microbiology, 1991. pp. 258-266.

O’Brien, K. Using focus groups to develop health surveys: An example from research on social relationships and AIDS-preventive behavior.Health Educ Q 20(3):361-372, 1993.

Page, J. Shooting scenarios and risk of HIV-1 infection. Am Behav Sc 33:478-490, 1990.

Pelto, P., and Pelto, G. Ethnography: The fieldwork enterprise. In: Honigmann, J., ed. Handbook of Social and Cultural Anthropology.Chicago: Rand McNally, 1973. pp. 241-288.

Pelto, P., and Pelto, G. Anthropological Research: The Structure of Inquiry. 2d ed. Cambridge, MA: Cambridge University Press, 1978.

Pfaffenberger, B. Microcomputer Applications in Qualitative Research .Sage University Paper Series on Qualitative Research Methods. Vol. 14. Newbury Park, CA: Sage Publications, 1988. Price, L. “Update on the Needle Hygiene Study.” Paper presented at the National Institute on Drug Abuse Cooperative Agreement Science .Meeting, Flagstaff, AZ, August 25 and 26, 1993. Punch, M. Politics and ethics in qualitative research. In: Denzin, N., and Lincoln, Y., eds. Handbook of Qualitative Research. Thousand Oaks, CA: Sage Publications, 1994. pp. 83-97. Richards, T., and Richards, L. Using computers in qualitative research. In: Denzin, N., and Lincoln, Y., eds. Handbook of Qualitative Research. Thousand Oaks, CA: Sage Publications, 1994. pp. 445-462.

Ruckdeschel, R. Qualitative research as a perspective. Social Work Res Abstr 21(2):17-21, 1985. Serrano, Y.; Faruque, S.; Lauffer, H.; Clatts, M.; Kipke, M.; LaFrance, S.; O’Connor, S.; Long, A.; Mills, S.; Wilber, J.; Geoffrey, J.;Cheney, R.; and Wiebel, W. Assessment of street outreach for HIV prevention: Selected sites, 1991-1993. MMWR 42:873, 879-880, 1993. 
Siegal, H. Gettin' it together: Some theoretical considerations on urban ethnography among underclass people. In: Weppner, R., ed. Street Ethnography: Selected Studies of Crime and Drug Use in Natural Settings. Beverly Hills, CA: Sage Publications, 1977. pp. 79-102.

Siegal, H. Intravenous drug abuse and the HIV epidemic in two midwestem cities: A preliminary report. J Drug Issues 20(2):281-290, 1990.

Siegal, H.; Carlson, R.; Wang, J.; Falck, R.; Stephens, R.; and Nelson, E. Injection drug users in the midwest: An epidemiologic comparison of drug use patterns in four Ohio cities.

J.Psychoactive Drugs26:265-275, 1994.

Singer, M. Confronting the AIDS epidemic among IV drug users: Does ethnic culture matter? AIDS Educ Prev 3:258-283, 1991.

Singer, M.; Jia, Z.; Schensul, J.; Weeks, M.; and Page, J. AIDS and the IV drug user: The local context in prevention efforts. Med Anthro14:285-306, 1992.

Sitton, T.; Mehaffy, G.; and Davis, O. Oral History: A Guide for Teachers (and Others). Austin: University of Texas Press, 1983.

Society for Applied Anthropology. Statement on professional and ethical responsibilities. Hum Organ 50(3):312, 1991.

Soloway, I., and Walters, J. Workin' the comer: The ethics and legality of ethnographic fieldwork among active heroin addicts. In: Weppner, R.,ed. Street Ethnography: Selected Studies of Crime and Drug Use in Natural Settings. Beverly Hills, CA: Sage Publications, 1977. pp. 159-177. Sterk-Elifson, C. Outreach among drug users: Combining the role of ethnographic field assistant and health educator. Hum Organ52:162-168, 1993.

Stewart, D., and Shamdasani, P. Focus Groups: Theory and Practice.Newbury Park, CA: Sage Publications, 1988.

Strauss, A., and Corbin, J. Basics of Qualitative Research: Grounded Theory Procedures and Techniques. Newbury Park, CA: Sage Publications, 1990.

Strauss, A., and Corbin, J. Grounded theory methodology: An overview. In: Denzin, N., and Lincoln, Y., eds. Handbook of Qualitative Research. Thousand Oaks, CA: Sage Publications, 1994. pp. 273-285.

Survey Research Center. Interviewer's Manual. Ann Arbor, MI: Institute for Social Research, University of Michigan, 1966.

Trotter, R., II, and Potter, J. Pile sorts, a cognitive anthropological model of drug and AIDS risks for Navajo teenagers: Assessment of a new evaluation tool. In: Fisher, D., and Needle, R., eds. 
AIDS and Community-Based Drug Intervention Programs: Evaluation and utreach. New York: The Haworth Press, 1993. pp. 23-39.

Vidich, A., and Stanford, M. Qualitative methods: Their history in sociology and anthropology. In: Denzin, N., and Lincoln, Y., eds. Handbook of Qualitative Research. Thousand Oaks, CA: Sage Publications, 1994. pp. 23-59.

Weller, S., and Romney, A. Systematic Data Collection. Sage University Paper Series on Qualitative Research Methods. Vol 10. Newbury Park, CA: Sage Publications, 1988.

Weppner, R. Street ethnography: Problems and prospects. In: Weppner, R., ed. Street Ethnography: Selected Studies of Crime and Drug Use in Natural Settings. Beverly Hills, CA: Sage Publications, 1977a. pp. 21-51.

Weppner, R., ed. Street Ethnography: Selected Studies of Crime and Drug Use in Natural Settings. Beverly Hills, CA: Sage Publications, 1977b.

Werner, O., and Schoepfle, G. Systematic Fieldwork. Vol. 1, Foundations of Ethnography and Interviewing. Newbury Park, CA: Sage Publications, 1987a.

Werner, O., and Schoepfle, G. Systematic Fieldwork. Vol. 2, Ethnographic Analysis and Data Management. Newbury Park, CA: Sage Publications, 1987b.

Wiebel, W. Identifying and gaining access to hidden populations. In: Lambert, E., ed. The Collection and Interpretation of Data from Hidden Populations. National Institute on Drug Abuse Research Monograph 98. HHS Pub. No. (ADM)90-1678. Washington, DC:

Supt. of Docs., U.S. Govt. Print. Off., 1990. pp. 4-11.

Williams, M., and Johnson, J. Social network structures: An ethnographic analysis of intravenous drug use in Houston, Texas. In: Fisher, D., and Needle, R., eds. AIDS and Community-Based Drug Intervention Programs: Evaluation and Outreach. New York: The Haworth Press, 1993. pp. 65-90.

\section{AUTHORS}

Robert G. Carlson, Ph.D.

Assistant Professor

Director of Ethnography

Harvey A. Siegal, Ph.D.

Professor and Principal Investigator

Russel S. Falck, M.A.

Project Director

AIDS Prevention Research Project

Substance Abuse Intervention Programs

Department of Community Health 
Wright State University School of Medicine

143 Biological Sciences Building

3640 Colonel Glenn Highway

Dayton, OH 45435 